\title{
A study on the evaluation of drug package inserts: a prospective observational study
}

\author{
Anita Hiraman Yuwnate, Ananya Chakravorty*
}

Department of Pharmacology, Government Medical College, Akola, Maharashtra, India

\author{
Received: 05 December 2019 \\ Revised: 31 January 2020 \\ Accepted: 01 February 2020 \\ *Correspondence: \\ Dr. Ananya Chakravorty, \\ Email: jhilikmail@gmail.com
}

Copyright: (c) the author(s), publisher and licensee Medip Academy. This is an open-access article distributed under the terms of the Creative Commons Attribution Non-Commercial License, which permits unrestricted non-commercial use, distribution, and reproduction in any medium, provided the original work is properly cited.

\begin{abstract}
Background: The package inserts are an important source of information for the patient and the prescribers which are often incomplete in terms of information. Not many of them are patient friendly, usage of technical terms further complicates the scenario amidst inadequate doctor-patient ratio. Aim of the study was to evaluate the completeness of package inserts.

Methods: Hundred package inserts were collected from June 2018 to September 2018 from nearby pharmacies and drug store of a tertiary care hospital, Government Medical College, Akola and evaluated in terms of completeness as per guidelines mentioned in the section D of Drug and Cosmetics Act 1945, language used and addressed to whom. Each guideline followed under section D was given a score of 1 and absence 0 depending upon which grouped as Grade A (>15), Grade B (10-15), Grade C (<10). Result was analysed in Microsoft Excel 2010 expressed in percentage and whole numbers.

Results: Out of the 100 package inserts evaluated the guidelines like mentioning of special circumstances like pregnancy was present in (98\%), undesirable effects in $98 \%$. All of them used English with $3 \%$ having combination with regional language, $70 \%$ had no mention as to whom it is addressed. Grades allotted after evaluation A, B, C, $24 \%, 74 \%, 2 \%$.

Conclusions: The present study showed though improvement occurred deficiencies should be corrected and properly scrutinised for better compliance of the patient and effective drug use and to step up the healthcare services in society.
\end{abstract}

Keywords: Addressed to whom, Language used, Package inserts, Section D of drug and cosmetics act 1945

\section{INTRODUCTION}

A package inserts also known as "prescription drug label or prescription information" is a document approved by the administrative licensing authority with precise, reliable, authenticated information and is provided with the package of the drug, is directed to prescribers as well as patients to provide information for safe and effective use of drugs. ${ }^{1}$
In India the doctor patient ratio is $1: 1700$ while the recommended doctor patient ratio is $1: 1000 .^{2,3}$ Hence it is difficult for doctor to impart detail information about the drug as well as for the patient to remember them. ${ }^{4}$ Since the oral information provided is missed, forgotten or misunderstood by the patient there is to certain extent dire need of written information provided to them in a language which is easily understood by them to use drugs judicially. ${ }^{5}$ 
Due to workload on the doctors of the developing countries and limited access to recent advances in relation to a particular drug under such circumstances as well the package inserts serve as a source of information for safe and effective drug use. ${ }^{6}$

Hence it is an important source of information addressing the physicians, pharmacists, drug administrators like nurses as well as for the patient. ${ }^{7}$

Regulatory authorities like USFDA EMA functional in different countries with different regulatory requirements regarding package inserts contents with amendments from time to time. ${ }^{8,9}$ In India regulatory authority is CDSCO and the regulation are provided under section 6.2 and 6.3 of Drugs And Cosmetics Act 1940 And Rules 1945 final amendment of which was enforced in 1986. ${ }^{10,11}$ The Drug and Cosmetics Act as well as Schedule Y (referring package insert as "prescribing information") does not specify the user of the package insert although however appears to be directed towards health care professionals. ${ }^{12}$

In India studies conducted on the quality and quantity of information in package insert highlighted deficiencies. $^{12,13}$ A study conducted by Shivkar et al although showed improvement in results regarding information on package insert from that conducted by Sethi et al still further improvement is required. ${ }^{12,13}$

Studies conducted in abroad like UAE and Denmark also showed less compliance of the package with regulations and international standards as well as confusing and inconsistent information in package inserts leading to reduced compliance among patients. ${ }^{14,15}$

Thus, present study was conducted to find out the improvement as well as completeness in terms of information in package inserts.

\section{METHODS}

A prospective observational study was carried out from June 2018 to September 2018 using 100 package inserts collected from different pharmacies of the locality and drug store of tertiary care hospital of Government Medical College, Akola covering different class of drug as well as different dosage forms and evaluated in terms of completeness as per guidelines mentioned in Section D of Drug and Cosmetics Act 1945 and language used and information regarding to whom it is addressed.

Each guideline of the Drug and Cosmetic Act 1945 that was followed was given a score of " 1 " and absence of it " 0 ". Depending on the score obtained 100 evaluated package inserts were grouped under as number of them under grade A (>15 score), grade B (10-15 score), grade C ( $<10$ score). Result was analysed in Microsoft Excel 2010 and was expressed as whole number and percentage.

\section{RESULTS}

Hundred package inserts were collected from local pharmacies as well as drug store of tertiary care hospital covering different class of drug used as well as different dosage forms. Maximum class of drug whose package insert was available was of antibiotics 60\% (Figure 1).

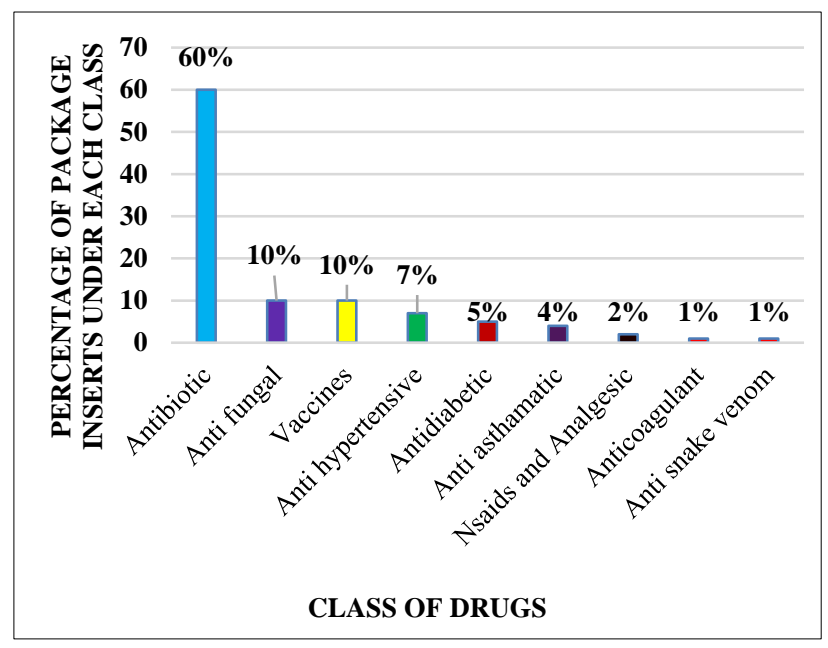

Figure 1: Classification of 100 package inserts on the basis of class of drug.

Maximum dosage route that was seen in the 100 collected package inserts were of oral dosage routes $82 \%$ (Figure 2).

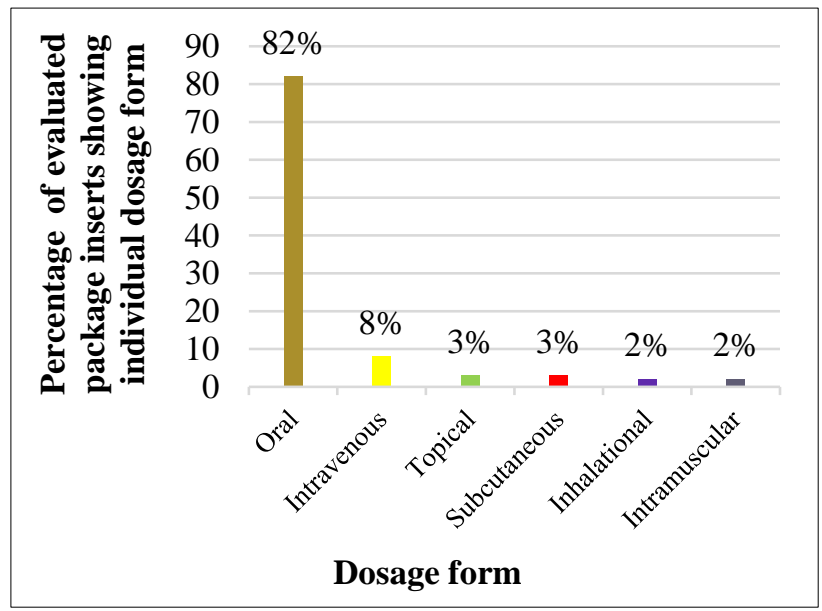

Figure 2: Percentage of 100 evaluated package inserts with the dosage route specified.

Among the 100 evaluated package inserts 98\% had special circumstances mentioned like pregnancy and lactation, 98\% had mentioned undesirable side effects, $80 \%$ had special precaution for storage as shown in (Table 1).

Among the 100 evaluated package inserts 24 of them were under grade $\mathrm{A}, 74$ of them were under grade $\mathrm{B}$, and 2 of them were under Grade C (Figure 3). 
Table 1: Percentage of the evaluated 100 package inserts with individual guidelines of the act.

\begin{tabular}{|l|l|}
\hline Guidelines of the act & $\begin{array}{l}\text { Percentage of } \\
\text { package inserts } \\
\text { complying with } \\
\text { the guidelines }\end{array}$ \\
\hline $\begin{array}{l}\text { Special circumstances like } \\
\text { pregnancy, lactation }\end{array}$ & 98 \\
\hline Undesirable effects & 98 \\
\hline Contraindications mentioned & 96 \\
\hline $\begin{array}{l}\text { Therapeutic indication } \\
\text { specified }\end{array}$ & 95 \\
\hline $\begin{array}{l}\text { Interactions with other } \\
\text { medications mentioned }\end{array}$ & 94 \\
\hline $\begin{array}{l}\text { Dose and method of } \\
\text { administration }\end{array}$ & 90 \\
\hline $\begin{array}{l}\text { Special warnings and } \\
\text { precautions }\end{array}$ & 80 \\
\hline Special precaution for storage & 80 \\
\hline $\begin{array}{l}\text { Shelf life after opening the } \\
\text { container }\end{array}$ & 70 \\
\hline Excipients used & 60 \\
\hline $\begin{array}{l}\text { Shelf life after } \\
\text { dilution/reconstitution }\end{array}$ & 50 \\
\hline $\begin{array}{l}\text { Antidote to be used in case of } \\
\text { overdose }\end{array}$ & 40 \\
\hline Instructions for use & 40 \\
\hline Incompatibility & 34 \\
\hline Effect on driving mentioned & 30 \\
\hline Pharmacokinetic & 20 \\
\hline $\begin{array}{l}\text { Nature and specification of the } \\
\text { container }\end{array}$ & 10 \\
\hline Shelf life for sale & 10 \\
\hline Retail price of the drug & 2 \\
\hline Reference of information & 9 \\
\hline
\end{tabular}

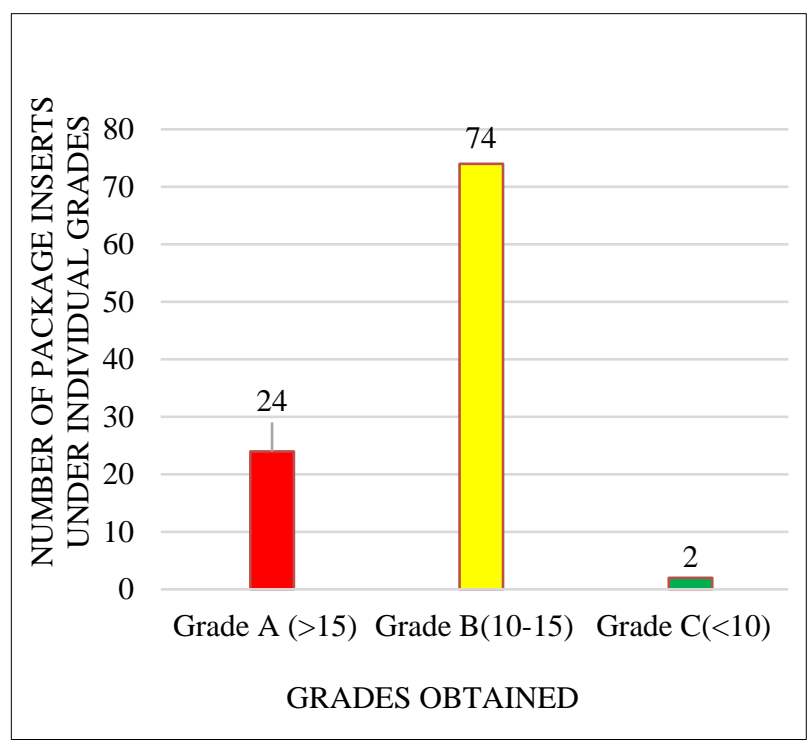

Figure 3: Grades of 100 evaluated package inserts obtained from the scoring of the individual guidelines.
Among the 100 evaluated package all of them used English language only $3 \%$ of them had a combination of English and regional language (Figure 4).

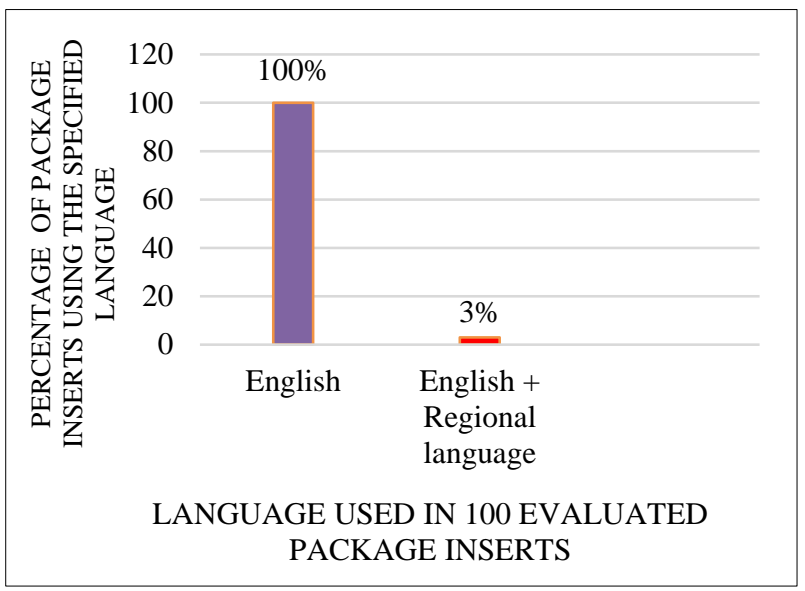

Figure 4: The usage of language in 100 evaluated package inserts.

Among the 100 package inserts evaluated $70 \%$ did not mention as to whom it is addressed (Figure 5).

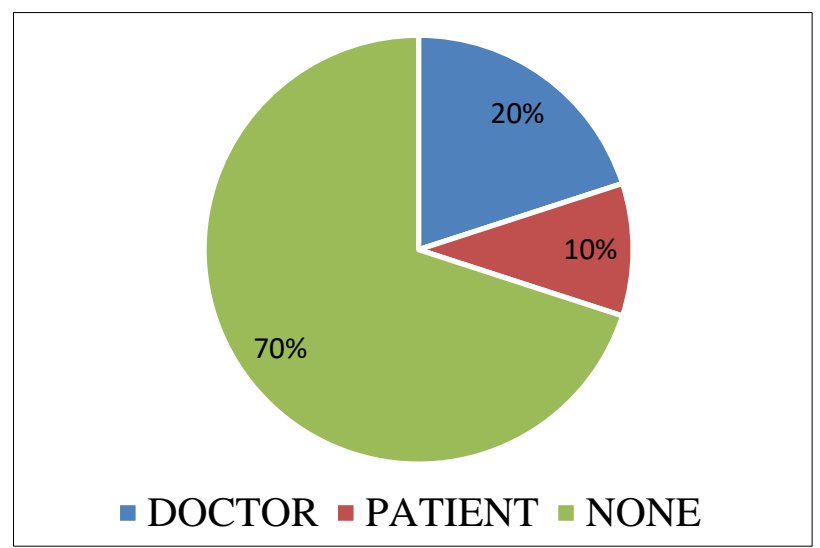

Figure 5: Percentage of package insert showing to whom it is addressed.

\section{DISCUSSION}

Package inserts are important source of information for prescribers and patients. Not only in India but also in countries like Europe, USA, Australia, Saudi Arabia substantial efforts are made for improvement of the information content of package inserts. ${ }^{16}$

The present study about package inserts carried out collecting package inserts available in local pharmacy as well as drug store of tertiary care hospital and was analysed, in the 100 package inserts analysed $60 \%$ of the package insert belonged to class of antibacterial and $82 \%$ of them belonged them had oral route of administration (Figure 1 and 2). Antibacterial class was also found maximum in studies conducted by Deepak et al, Sudhamadhuri et al and Shruti et al. ${ }^{17,1,19}$ Oral as route of 
administration was found maximum in Deepak et al, Sudhamadhuri et al, Sudha et al, Kalam et al and Shruti et al. ${ }^{1,17,19-21}$

As per the guidelines evaluated according to Drugs and Cosmetic Act 1945 (Table 1) undesirable effects were mentioned in $98 \%$ of the evaluated package inserts which is more as compared to studies conducted by Deepak et all where it was mentioned only in $37.69 \%$ and Chhaya et al where it was mentioned in $97 \%$ of the evaluated package inserts. ${ }^{17,22}$ In the present study pregnancy and lactation was mentioned in $98 \%$ of the evaluated package inserts which is more in comparison to study conducted by Deepak et al where it was mentioned in $37.69 \%$ and Chhaya et al where it was mentioned in $89 \%$ and Sudha et al where it was mentioned in $84 \% .^{17,20,22}$ As per the guidelines mentioning of Method of administration and precautions of use as found out in present study was $80 \%$ and $90 \%$ which was similar to the study conducted by Sudhamadhuri et al. ${ }^{1}$ In present study antidote was mentioned in $40 \%$ of the evaluated package 100 package inserts which was more compared to studies conducted by Sudhamadhuri et al where only $20 \%$ is mentioned, $13 \%$ in a study conducted by Chhaya et al and Kalam et al where it is mentioned in only $4 \% \cdot \cdot^{1,21,22}$ In the present study contraindication was present in $96 \%$ of the evaluated package inserts which was similar to a study conducted by Chhaya et al however more than the result as obtained by Shruti et al and Sowmya et al which was $91 \% \cdot{ }^{19,22,23}$ In the present study special mention about driving was present in $30 \%$ of the evaluated package inserts as compared to $2 \%$ in a study conducted by Kalam et al, $16 \%$ in a study conducted by Chhaya et al, $13 \%$ in a study conducted by Sudha et al and $17 \%$ by Shruti et al. ${ }^{19-22}$ Excipicents where mentioned in $60 \%$ of the present study as compared to the study conducted by Sudhamadhuri et al $120 \%$ and $12 \%$ in a study conducted by Chhaya et al. ${ }^{22}$ Storage information was present in $80 \%$ of the present study compared to $62 \%$ in a study conducted by Sudhamadhuri et al and $58 \%$ in a study conducted by Kalam et al. ${ }^{1,21}$ Interaction with other medications was mentioned in $94 \%$ of the package inserts evaluated as compared $89 \%$ in a study conducted by Chhaya et al and $90 \%$ as compared to Sudha et al and only $12 \%$ as found in a study conducted by Kalam et al. ${ }^{20-22}$ In the present study shelf life after dilution and after sale was present in $50 \%$ and $10 \%$ whereas it was absent in a study conducted by Deepak et al. ${ }^{17}$ Retail price was present in $2 \%$ of the evaluated package inserts however absent in Deepak et al and Shruti et al. ${ }^{17,19}$

In the present study most of the evaluated package inserts belonged to Grade B (Figure 3) which was similar as seen in a study conducted by Deepak et al and Shruti et al. ${ }^{17,19}$

In the present study most of the evaluated package inserts were written in English as compared to other studies as well (Figure 4).
Due to in adequate doctor patient ratio in India and workload it makes it all the more difficult for the physician to give enough time to patients giving rise to medication errors and reduced compliance. Hence patient oriented Package inserts are necessary devoid of technical terms. Currently in India all package inserts are mostly directed towards the prescribers. In the present study as well $70 \%$ was directed to the prescribers (Figure 5) similar to that found by Sudha et al, Kalam et al and Sudhamadhuri et al in their respective study..$^{1,20,21}$

The present study was conducted with the package inserts available local pharmacy and medical store of a tertiary care hospital hence more wide scale study covering different pharmacy as well as hospitals in a region should be done for more better evaluation.

Company wise distribution was not done in the present study however it should be done to see whether information regarding different brands of same drug launched by different companies provide uniform information were the few limitations of this study.

\section{CONCLUSION}

Though the present study has shown some improvement from the studies conducted in the past still further improvement is required. Package insert should be more patient oriented without the use of technical terms specially in country like India where over the counter medication is rampant as well as inadequate doctor patient ratio.

Since India is a multilingual country availability of package insert in all languages would be difficult hence more of pictographic presentation specially of side effects and methods of administration should be emphasized for better understanding and compliance of the patient.

\section{ACKNOWLEDGEMENTS}

Authors would like to thank all the staff members of the drug store at tertiary care hospital and the nearby pharmacies for their continuous help.

Funding: No funding sources

Conflict of interest: None declared

Ethical approval: The study was approved by the Institutional Ethics Committee

\section{REFERENCES}

1. Sudhamadhuri A, Kalasker V. Evaluation of completeness of package inserts in south India. Inter J Res Stud Biosci. 2015;3(7):102-5.

2. Kumar A. India has just one doctor for every 1,700 people. The New Indian Express, 2013. Available at: http://www.newindianexpress.com/ magazine/ Indiahas-just-one-doctor-for-every-1700-people/ 2013/ 09/ 22/article1792010.ece. Accessed 05 May 2016. 
3. Deo MG. Doctor population ratio for India-The reality. Ind J Med Res. 2013;137(4):632.

4. Khan TM, Hassali MA, Al-Haddad MS. Patientphysician communication barrier: A pilot study evaluating patient experiences. J Young Pharmacists. 2011;3(3):250-5.

5. Mahatme MS, Dakhale GN, Hiware SK, Wankhede SS, Salve AM, Mahatme SR. Comparison of Indian package inserts in public and private sector: an urgent need for self-regulation. Int $\mathrm{J}$ Basic Clin Pharmacol. 2013;2(2):165-9.

6. Gupta VK, Pathak SS. Assessment of awareness and knowledge about package inserts amongst medical students: a questionnaire-based study. IOSR J Pharm. 2012;2(2):215-7.

7. Joubert PH, Skene DE. Attitudes of private medical practitioners towards package inserts and other drug information sources. South African Med J. 1984;66(8):306-7.

8. Food and Drug Administration, HHS. Requirements on content and format of labelling for human prescription drug and biological products. Final rule. Federal Register. 2006;71(15):3921.

9. European Medicines Agency. Guideline on the Packaging Information of Medicinal Products for Human Use Authorised by the Community. February 2008. Available at: http://ec.europa.eu/enterprise /pharmaceuticals/eudralex/vol2/c/bluebox_02_2008.p df. Accessed 12 July 2012.

10. Kalam A, Anwar S, Fatima A. Drug package inserts in India: current scenario. World J Pharma Pharmaceutical Sci. 2014;3(4):385-92.

11. Govt. of India, Ministry of Health and Family Welfare. Drug and Cosmetics Rules, 1945. Available at: http://cdsco.nic.in/html/DrugsandCosmeticAct. pdf. Accessed 12 Feb 2012.

12. Shivkar YM. Clinical information in drug package inserts in India. J Postgrad Med. 2009;55(2):104.

13. Lal A, Sethi A. Drug package inserts in India. Ann Pharmacother. 1996;30(9):1041.
14. Gharibyar H, Sharif Y. Evaluation of pharmaceutical drug information brochures in the Emirate of Abu Dhabi (United Arab Emirates). J Pharmaceutical Health Services Res. 2012;3(1):57-62.

15. Bjerrum L, Foged A. Patient information leafletshelpful guidance or a source of confusion?. Pharmacoepidemiol Drug Safety. 2003;12(1):55-9.

16. Al-Aqeel SA. Evaluation of medication package inserts in Saudi Arabia. Drug, Healthcare Patient Safety. 2012;4:33

17. Ramdas D, Chakraborty A, Swaroop HS, Faizan S, Kumar P, Srinivas BN. A study of package inserts in southern India. J Clini Diagnos Res: JCDR. 2013;7(11):2475.

18. Sudhamadhuri A, Kalasker V. Evaluation of completeness of package inserts in south India. Inter J Res Studies Biosci. 2015;3(7):102-5.

19. Shruti DA, Sarala N, Bhuvana K. Analysis of package inserts of drugs utilized in a tertiary care hospital. J Young Pharm. 2016;8(3):275-8.

20. Sudha MJ, Viveka S, Remya S, Udupa A. L. Drug package inserts: how accessible is the information?, Inter J Basic Clini Pharmacol. 2015;4:1132-5.

21. Kalam A, Anwar S, Fatima A. Drug package inserts in India: current scenario. World J Pharma Pharmaceutical Sci. 2014;3(4):385-92.

22. Chhaya MU. Analysis of package inserts of orally administered drugs available in the Indian market. Inter J Res Med Sci. 2017;5(2):529-32.

23. Sowmya B, Vijayalakshmi, Narayana R. Critical appraisal of patient package inserts in allopathic medicines. J Chem Pharm Res. 2015;7(3):1805-8.

Cite this article as: Yuwnate AH, Chakravorty A. A study on the evaluation of drug package inserts: a prospective observational study. Int J Basic Clin Pharmacol 2020;9:441-5. 